\title{
INFORMATION FOR CONTRIBUTORS TO
}

\section{QUARTERLY REVIEWS OF BIOPHYSICS}

1. Quarterly Reviews of Biophysics is the official journal of the International Union for Pure and Applied Biophysics. As such, its primary aim is to provide a forum for general and specialized communication between biophysicists working in different areas. This will normally be achieved by inviting authors who have made significant contributions to give a critical and readable account of recent progress in their special fields. Shorter and even controversial articles discussing topics of particular current interest will also be published.

2. Reviews should preferably be written in English. The style of presentation must be concise, with only key references.

3. Three copies of manuscripts are required. They should be typed in double spacing with a margin of $4 \mathrm{~cm}$ all round. The position of tables and illustrations should be indicated in the text. Tables and legends for illustrations should be typed on separate pages. A table of contents should be provided for printing at the head of the article.

4. In the text, the references should be to authors and year. When a paper cited has three or more authors the style Smith et al. (1973) should be used on all occasions. At the end of the paper, references should be listed alphabetically, with the full title of each paper, and the first and last pages. Abbreviations of journal titles should follow the latest edition of the World List of Scientific Periodicals. For exampie

BERnal, J. D. (1967). Origin of Life. London: Weidenfeld and Nicolson.

Eigen, M. (ig68). New looks and outlooks on physical enzymology. $Q$. Rev. Biophys. 1, 3-33.

5. Drawings should be in Indian ink on tracing paper. They should be drawn roughly twice the size of the finished block. Explanations should as far as possible be placed in the legends. Lettering for photographs should either be on a duplicate print or on an accurately registered overlay.

6. The author will receive only one set of page proofs for correction. Fifty reprints of each review will be provided free of charge. Additional copies may be purchased. 


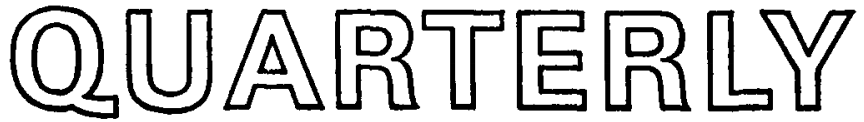

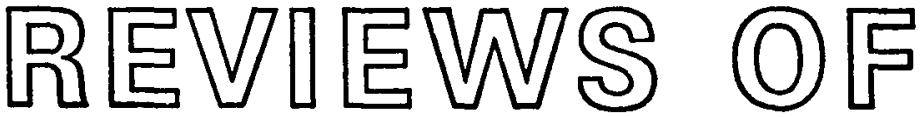 BUOPUYSLCS}

A Review on the following topic will appear in a forthcoming issue:

Genetics of the Nervous System in Drosophila

JEFFREY C. HALL

(c) Cambridge University Press 1982

CAMBRIDGE UNIVERSITY PRESS

The Pitt Building, Trumpington Street, Cambridge CB2 IRP 32 East 57th Street, New York, NY 10022 